\title{
Mathematical Model Indicates Nonlinearity of Noradrenaline Effect on Rat Renal Artery
}

\author{
M. ĎURIŠOVÁ ${ }^{1}$, L. DEDÍK ${ }^{1,2}$, V. KRISTOVÁ ${ }^{3}$, R. VOJTKO $^{3}$ \\ ${ }^{1}$ Institute of Experimental Pharmacology, Slovak Academy of Sciences, ${ }^{2}$ Faculty of Mechanical \\ Engineering, Slovak University of Technology and ${ }^{3}$ Department of Pharmacology, Medical School, \\ Comenius University, Bratislava, Slovak Republic.
}

Received January 23, 2007

Accepted October 11, 2007

On-line October 11, 2007

\section{Summary}

The aim of this work is to present the efficacy of a previously introduced computational procedure, developed for evaluation of vascular responsiveness. On this reason, as an example a common study of noradrenaline (NA) effect on a rat renal artery under in vitro conditions was arbitrarily selected. The response of the arterial segment to NA doses (0.1-10 $\mu \mathrm{g})$ was digitally recorded on a PC and employed to develop mathematical model of NA effect. Using the model, the following NA effect variables were determined: the vessel sensitivity parameter, mean effect time and rate constant, respectively, characterizing the effect intensity, duration, and regression and also classic response variables: the maximal effect and time of the maximal effect. The two-way analysis of variance followed by Bonferroni's test revealed a significant influence of the increasing NA dose on the vessel sensitivity parameter and mean effect time. These findings indicated nonlinearity of processes underlying NA effect on the rat renal artery over the given range of NA doses. The procedure exemplified has the potential for use as an effective adjunct to routine studies of vascular responsiveness as it enables the extraction of meaningful information which cannot by obtained by common manual evaluation procedures.
\end{abstract}

\section{Key words}

Computational method $\bullet$ Digital recording $\bullet$ Sensitivity parameter - Mean effect time $\bullet$ Effect regression

\section{Corresponding author}

L. Dedik, Faculty of Mechanical Engineering STU, 17 Námestie slobody, Bratislava 812 31, Slovak Republic. Fax: +421 25729 4559, E-mail: ladislav.dedik@stuba.sk
Vascular responsiveness to biologically active substances under in vitro conditions is commonly investigated by measurement of responses of vessel segments and registration of the responses on analogous recorders. Subsequently, response descriptive variables such as the maximal response, half-maximal response, time to reach the maximal response are determined by manual evaluation of registered profiles (Kristová et al. 1993, Ralevic et al. 1998, Duncan et al. 2004). The manual evaluation is potentially inaccurate and poorly reproducible. Hence there is an increasing need for a computational evaluation procedure. We therefore introduced the procedure for a computational evaluation of vascular responsiveness in our pilot study (Dedík et al. 2003). The procedure enables to develop a mathematical model that provides a description of an effect of a biologically active substance on a vessel segment. Using the model, the following effect variables can be determined: the vessel sensitivity parameter, mean effect time and rate constant, respectively, characterizing the effect intensity, duration, and regression (Dedík et al. 2003). The most important significance of the vessel sensitivity parameter and mean effect time is that these variables are constant over such a range of doses of the biologically active substance over which the processes underlying the effect of the substance on the vessel segment are linear, i.e. the vessel response varies in direct proportion to the substance dose (Dedík et al. 2003). Using mathematical models classic response descriptive variables (the maximal effect and time of the maximal 
Table 1. Noradrenaline (NA) effect on rat renal artery.

\begin{tabular}{lllll}
\hline NA dose $(\mu \mathrm{g})$ & 0.1 & 0.5 & 1 & 10 \\
NA concentration $($ (nmol/l) & 23.7 & 118.3 & 236.7 & 2370 \\
Vessel sensitivity parameter $(\mathrm{kPa} / \mu \mathrm{g})$ & $179.6 \pm 52.1$ & $573.8 \pm 86.2^{*}$ & $740.3 \pm 110.5^{*}$ & $2687.1 \pm 634.3^{*}$ \\
Mean effect time $(\mathrm{s})$ & $55.6 \pm 13.1$ & $78.6 \pm 19.2$ & $108.7 \pm 30.5^{*}$ & $265.3 \pm 56.7^{*}$ \\
Rate constant of the effect regression $\left(\mathrm{s}^{-1}\right)$ & $0.019 \pm 0.006$ & $0.009 \pm 0.0008^{*}$ & $0.006 \pm 0.0007^{*}$ & $0.004 \pm 0.0007^{*}$ \\
Time of the maximum effect $(\mathrm{s})$ & $17.1 \pm 7$ & $25.9 \pm 8.2$ & $31.7 \pm 9.5^{*}$ & $57.3 \pm 10.6^{*}$ \\
Maximum effect $(\mathrm{kPa})$ & $1.4 \pm 0.8$ & $4.6 \pm 0.9^{*}$ & $7.7 \pm 2.1^{*}$ & $13.1 \pm 3.5^{*}$ \\
\hline
\end{tabular}

Data are expressed as arithmetic means \pm S.D. ${ }^{*}$ significant difference $(p<0.05)$ when compared with the variable corresponding to the NA dose of $0.1 \mu \mathrm{g}$.

effect) can also be determined. The goal of this work is to provide a next example of the use of the computational evaluation procedure (Dedík et al. 2003), i.e. the investigation whether NA effect on the rat renal artery under in vitro conditions exhibits linearity or not for noradrenaline doses ranging from 0.1 to $10 \mu \mathrm{g}$.

The detailed description of the materials, experimental procedures, response recording, and modeling procedure utilized in this work is given in our pilot study (Dedík et al. 2003), therefore only a brief summary is given here. Adult male Wistar rats of either sex (n=6; 300-420 g; Dobrá Voda, Slovakia) were used. The experiments were approved by the Ethical Committee for Animal Welfare of the Comenius University, Bratislava. Animals were killed by cervical dislocation. Renal arteries were excised together with kidneys and transferred into Tyrode's solution. Vessel segments of the renal arteries were cut up and placed into a bath, perfused with Tyrode's solution. After an equilibration period, vessel segments were exposed to NA doses of $0.1,0.5,1$ or $10 \mu \mathrm{g}$. NA hydrogentartrate (Léčiva, Prague, Czech Republic) was utilized. The segment responses were measured by a tensometric transducer and digitally registered as electronic signals on a PC. Signals were for modeling purposes converted from the voltage unit $(\mathrm{mV})$ to the pressure unit $(\mathrm{kPa})$ and the data number of the signals was reduced. Thereafter, transfer-function models (Ljung 1999, Dedík et al. 2003, Dedík and Duurišová 1995, Ďurišová and Dedík 1997, Ďurišová and Dedík 2002) that provided mathematical descriptions of NA effect were developed for all vessel segments and NA doses. The model development was based on the crucial assumption that processes underlying the NA effect are time-invariant, i.e. that no temporal variation was present. Subsequently, on the basis of the models, the following effect variables were determined for all vessel segments and NA doses: the vessel sensitivity parameter, mean effect time, and the rate constant of the effect regression. Besides the given new variables also classic descriptive variables of responses were determined: the maximum effect and time of maximum effect, using the developed models. Two-way analysis of variance (ANOVA) followed by Bonfferoni's test were used to evaluate the variables. Differences among the variables were considered significant when $\mathrm{p}<0.05$.

To illustrate the modeling results, one vessel segment and the response of selected segment to NA dose of $1 \mu \mathrm{g}$ was arbitrarily chosen as the representative. The time course of the registered signal of the selected response is shown in Figure 1a. The transfer-function model $H(s)$ of NA effect on the selected segment and NA dose of $1 \mu \mathrm{g}$ is given by Eq. 1

$$
H(s)=S \frac{a_{0}+a_{1} s}{1+b_{1} s+b_{2} s^{2}+b_{3} s^{3}},
$$

where $S$ is the vessel sensitivity parameter, $a_{0}, a_{1}, b_{1}, b_{2}$, and $b_{3}$ are additional model parameters, and $s$ is the Laplace variable (Dedík et al. 2003). The optimal values ( \pm S.D.) of the model parameters were: $S=655.07 \pm 19.65$ $\mathrm{kPa} / \mu \mathrm{g} ; a_{0}=1 \pm 0.03 \mathrm{~s} ; a_{1}=24.32 \pm 0.09 \mathrm{~s}^{2} ; b_{1}=120.57 \pm 9.41$ s; $b_{2}=2552.51 \pm 156.48 \mathrm{~s}^{2}$; and $b_{3}=32478.52+1034.5 \mathrm{~s}^{3}$. Based on the model (Eq. 1) the following variables were determined: the mean effect time of $96.25 \mathrm{~s}$, the rate constant of the effect regression of $0.011 \mathrm{~s}^{-1}$, time of the maximum effect of $30.55 \mathrm{~s}$, and the maximum effect of $6.85 \mathrm{kPa}$. The output of the transfer-function model (Eq. 1), i.e. the model of the response shown in Figure 1a, is presented in Figure $1 \mathrm{~b}$. Models analogous to that described by Eq. 1 were selected for all vessel segments and all NA doses.

Table 1 summarizes the variables of NA effect for all NA doses. ANOVA followed by the Bonfferoni's test revealed the significant influence of the increasing 


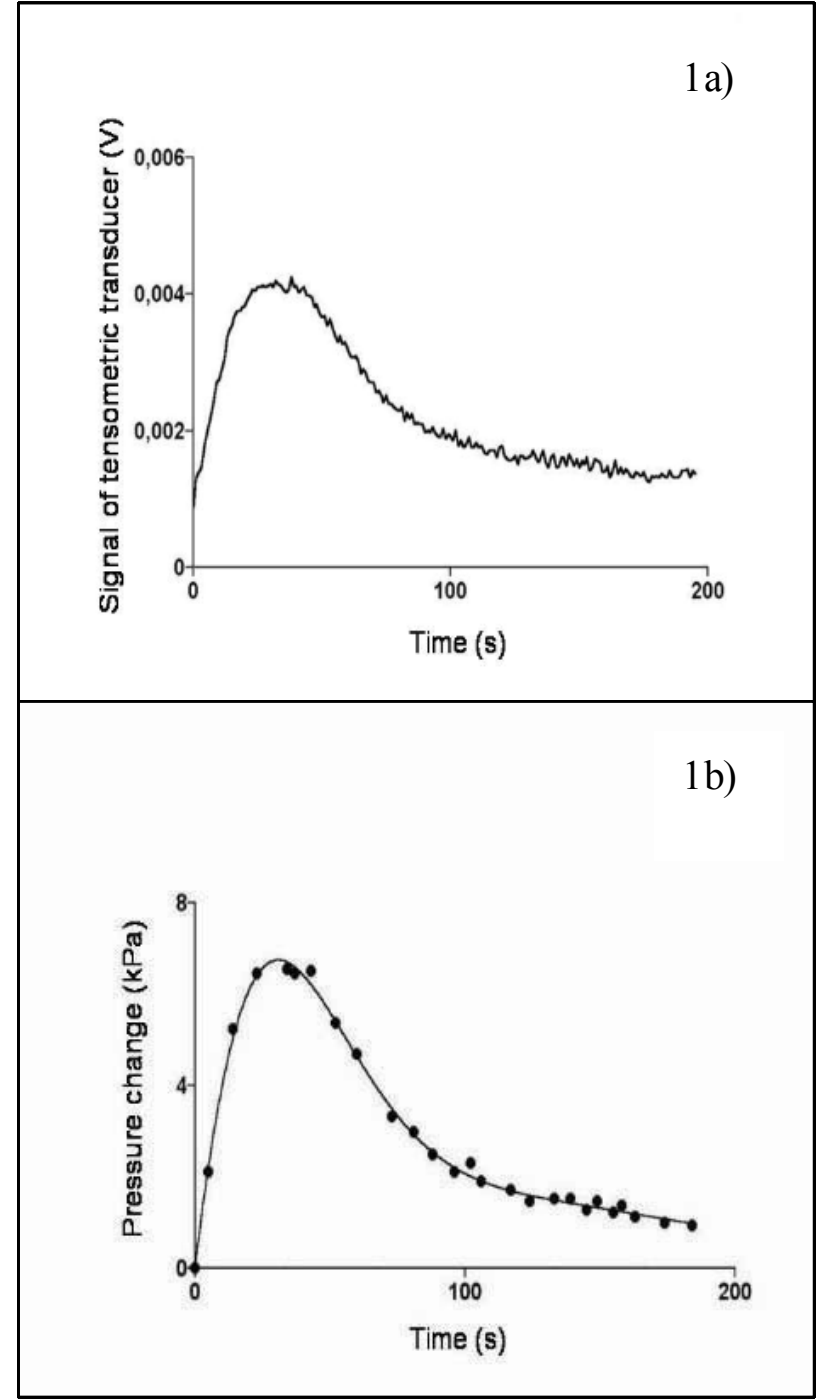

Fig. 1. Response of the selected vessel segment to noradrenaline dose of $1 \mu \mathrm{g}$. a) The row electronic signal digitally registered on a PC (intermittent line). b) The signal after the data-number reduction procedure (points). The approximation of the signal by the output of the model expressed by Eq. 1 (smooth line).

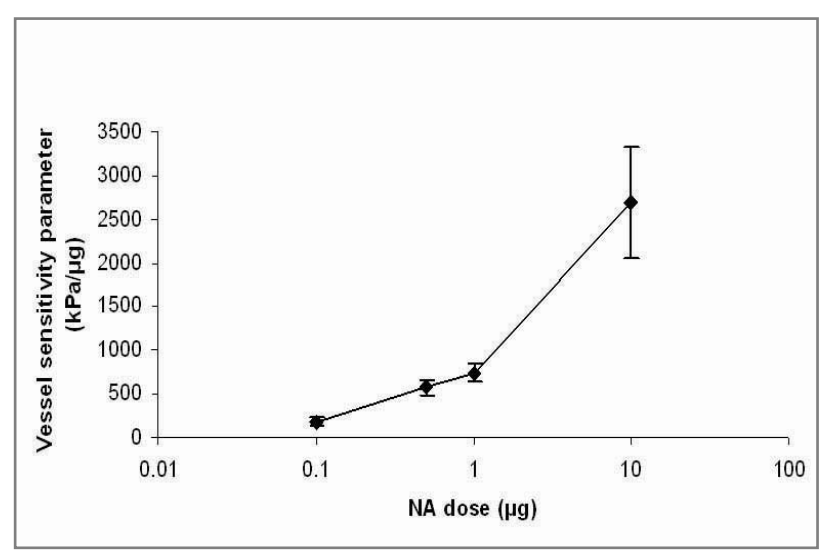

Fig. 2. Variation of the vessel sensitivity parameter with the noradrenaline dose.
NA dose on the vessel sensitivity parameter and mean effect time. These findings indicated nonlinearity of the processes underlying the NA effect on rat renal artery under in vitro conditions over the interval of NA doses used. As seen in Table 1, the vessel sensitivity parameter and mean effect time significantly increased with the increasing NA dose. The given statistical tests also revealed the significant effect of the increasing NA dose on the rate constant of the regression of NA effect, time to reach the maximal NA effect, and the maximal NA effect. The vessel sensitivity parameter, i.e. representative variable of the NA effect, was arbitrarily selected to exemplify the variance of the NA effect variables with the NA dose (Fig. 2).

The results of this study indicated nonlinearity of processes underlying NA effect on the rat renal artery under in vitro conditions. For explanation of mechanisms controlling these processes, a further research would be necessary. The computational procedure developed for evaluation of vessel responsiveness (Dedík et al. 2003) and utilized in this work is based on the theory of linear dynamic systems (Ljung 1999). The modeling part of this procedure starts with a non-iterative method and thus it does not require initial estimates of model parameters. Both these facts markedly simplify and speed up the procedure http://www.uef.sav.sk/advanced.htm. The procedure is highly reproducible and has the potential for use as an effective adjunct to routine studies of the vascular responsiveness under in vitro conditions as it enables the extraction of meaningful information that cannot by obtained by commonly utilized manual evaluation procedures. The development of computational approaches to pharmacological research will undoubtedly continue, and this study is a contribution to this effort.

\section{Conflict of Interest}

There is no conflict of interest.

\section{Acknowledgements}

This work was supported in part by the project BioSim a Network of Excellence, established by the European Commission under its $6^{\text {th }}$ Framework Program. The authors thank the reviewer for the helpful comments. This work is related to activities of authors L. Dedík and M. Durišová in Actions B22 and B25 of the COST program. 


\section{References}

DEDÍK L, ĎURIŠOVÁ M, SVRČEK V, VOJTKO R, KRISTOVÁ V, KRIŠKA, M: Computer-based methods for measurement, recording, and modeling vessel responses in vitro: a pilot study with noradrenaline. Methods Find Exp Clin Pharmacol 25: 441-445, 2003.

DEDÍK L, ĎURIŠOVÁ M: CXT - a program for analysis of linear dynamic systems in the frequency domain. Int $J$ Biomed Comput 39: 231-241, 1995.

DUNCAN M, KENDALL DA, RALEVIC V: Characterization of cannabinoid modulation of sensory neurotransmission in the rat isolated mesenteric arterial bed. J Pharmacol Exp Ther 311: 411-419, 2004.

ĎURIŠOVÁ M, DEDÍK L: Modeling in frequency domain used for assessment of in vivo dissolution profile. Pharmaceut Res 14: 860-864, 1997.

ĎURIŠOVÁ M, DEDÍK L: A system approach method for the adjustment of time-varying continuous drug infusion in individual patients: a simulation study. J Pharmacokinet Pharmacodyn 29: 427-444, 2002.

KRISTOVÁ V, KRIŠKA M, CAŇOVÁ R, HEJDOVÁ E, KOBZOVÁ D, DOBROCKÝ P: Endothelial changes following repeated effect of vasoconstrictive substances in vitro. Acta Physiol Hung 81: 363-370, 1993.

LJUNG L: System Identification - Theory for the User. Upper Saddle River, PTR Prentice Hall, 1999.

RALEVIC V, KNIGHT, G, BURNSTOCK G: Effects of hibernation and arousal from hibernation on mesenteric arterial responses of the golden hamster. J Pharmacol Exp Ther 287: 521-526, 1998. 